\title{
Ortaokul Öğrencilerinin Çevre Okuryazarlığı Alt Boyutlarının Çeşitli Değişkenler Açısından İncelenmesi
}

\begin{abstract}
Mustafa AKILLI*
Murat GENÇ **

Öz

Bu araştırmanın amacı ortaokul öğrencilerinin, çevre okuryazarlığı alt boyutlarının farklı değişkenler açısından incelenmesidir. Çalışmanın örneklemi Düzce ve Bartın illerinde yer alan toplam 8 okuldan seçilmiştir. Çevre okuryazarlığına ait alt boyutların düzeyini belirlemek için bilgi testi, davranış, tutum ve duyuşsal eğilim ölçekleri kullanılmıştır. Ayrıca öğrencilerin demografik özelliklerinin belirlenmesi için kişisel bilgi formundan yararlanılmıştır. 713 öğrenciye uygulanan anketlerden elde edilen veriler SPSS yardımıyla analiz edilmiştir. Çalışma sonucunda ortaokul öğrencilerinin cinsiyetlerinin çevre okuryazarlığı alt boyutlarından sadece davranış için fark oluşturduğu, sınıf düzeyinin artmasıyla tüm boyutlar için düzeylerin arttığı görülmüştür. Bunun yanı sıra babası üniversite bitirmiş olan öğrenciler ile anneleri lise mezunu olan öğrencilerin alt boyut puanları diğer mezuniyet derecesine sahip ebeveynlere göre farklılık göstermiştir.
\end{abstract}

Anahtar Kelimeler: Çevre okuryazarlı̆̆ı, bilgi, davranış, tutum, duyuşsal eğilim, çevre eğitimi.

\section{Examination of Middle School Students' Sub-Dimensions of Environmental Literacy in Terms of Various Variables}

\begin{abstract}
The aim of this study is to demonstrate middle school students' environmental literacy levels (as a combination of 4 sub-dimension) in terms of different factors. Sample of the study was chosen from 8 schools in Duzce and Bartın cities. In order to determine students' literacy levels 3 scales (behaviour, tendency and attitude) 1 knowledge test were used. Also a "personal information form" was used to gather information about students' sex, class and parent's education degree. Scale was administered to 713 students and results evaluated by SPSS packet programme with the help of independent $t$ test and one way ANOVA. As result, it is found that sex effect environmental literacy only in behaviours. At higher class levels the points of students are increasing with a meaningful difference. For their parents' education level, students' that have high school graduated mothers and bachelor's degree fathers have higher means than other parents.
\end{abstract}

Keywords: Environmental literacy, knowledge, behaviour, attitude, tendency, environmental education.

\footnotetext{
*Yrd. Doç. Dr., Düzce Üniversitesi, Eğitim Fakültesi, mustafaakilli@duzce.edu.tr
}

${ }^{* *}$ Yrd. Doç. Dr., Düzce Üniversitesi, Eğitim Fakültesi, muratgenc@duzce.edu.tr 


\section{GİRISŞ}

Çevre, canlıların hayati bağlarla bağlı olduklarl, etkiledikleri ve etkilendikleri doğal ortamlardır (Atasoy, 2006). Bu yüzden çevrenin çeşitli müdahalelerle değişmesi o ortamı paylaşan tüm canlıları etkilemektedir. İnsanoğlunun son dönemlerde doğaya olan etkisi üzücü bir şekilde olumsuz yönleri ağır basacak şekilde artmaya başlamıştır. İnsan hayatı ve çevre, birbirlerine bağlı olduğu için çevre insanlık için önemlidir. Her ikisinin de dengeli bir şekilde ömürlerine devam etmesi önemlidir. Ancak kentleşme, hızlı nüfus artışı, gelişen teknoloji ve sanayi ile birlikte çevre sorunları artış göstermektedir. Bu çevre sorunları insan hayatını da tehdit etmeye başlamıştır. Ortaya çıkan bu olumsuz gelişmelerden sonra insanlar bireysel veya örgütlü olarak harekete geçmiştir.

Çevre ile ilgili olarak örgütsel çalışmalar ilk önce Birleşmiş Milletler tarafından organize edilmiş ve 1972 'de çevre konulu ilk toplantısı Stockholm'de yapılmıştır. Zamanla çevre eğitimi üzerine farklı toplantı ve programalar düzenlenmiştir (1977 Tiflis Bildirgesi, 1992 Rio Toplantısı). Bu örgütlenmeler ile toplumların bilinçlendirilmesi ve çevre sorunlarına dikkat çekilmesi ve bu sayede sürdürülebilir yaşam şartlarının sağlanması amaçlanmıştır. Sürdürülebilir yaşam için bireylerin çevrenin korunması ile ilgili tutum, değer, bilgi, beceri ve davranışlar kazanması önem kazanmaktadır. Çevre eğitimi bu sebepten dolayı hayati bir önem taşımaktadır.

Çevre eğitimi programlarının en önemli hedeflerinden birisi çevre okuryazarlığıdır (Disinger ve Roth, 1992; Hungerford, Peyton, ve Wilke, 1980; Iozzi, Laveault, ve Marcinkowski, 1990). Çünkü çevre sorunlarıyla başa çıkmanın en etkili yolu olarak çevre okuryazarlığı gösterilmektedir (Balkan Kıyıcı, 2009). Literatür incelendiğinde çevre okuryazarlığının farklı dönemlerde farklı sayıda boyutlara göre tanımlandığı anlaşılmaktadır. Bu çalışmalarda öne çıkan çevre okuryazarlığı kaç boyutta olursa olsun bilgi, tutum ve davranış boyutlarının ortak olarak dile getirilmesi ve en önemli bileşenleri olarak ifade edilmesidir. Bazı çalışmalarda ise eğilim kavramının tanımı içinde yer alan diğer başlıklar (örneğin; değer, duyarlık, sorumluluk gibi) alt boyut olarak belirtilmektedir. Aşağıdaki tabloda bazı çalışmalarda bu alt boyutların hangileri olduğu özetlenmeye çalışılmıştır:

Tablo 1. Çevre okuryazarlığı alt boyutlarını ifade eden bazı çalışmalar

\begin{tabular}{|c|c|}
\hline $\begin{array}{c}\text { Çevre okuryazarlığ alt boyutlarını "bilgi", "tu- } \\
\text { tum" ve "davranış" olarak } 3 \text { boyutta ele alan bazı } \\
\text { çalışmalar }\end{array}$ & $\begin{array}{c}\text { Çevre okuryazarlığı alt boyutlarına temel alınan } 3 \\
\text { boyuttan farklı olarak eğilim boyutunu dahil eden } \\
\text { bazı çalışmalar }\end{array}$ \\
\hline Cheng ve $\mathrm{Wu}(2015)$ & Wang (2014) \\
\hline Bergman (2015) & Karatekin ve Aksoy (2012) \\
\hline Fah ve Sirisena (2014) & Altınöz (2010) \\
\hline Karatekin (2011) & Teksöz, Şahin ve Ertepınar (2010) \\
\hline Digby (2010) & Erdoğan (2009) \\
\hline Yavetz, Goldman ve Pe'er (2009) & Kışoğlu (2009) \\
\hline Negev, Sagy, Garb, Salzberg ve Tal (2008) & Owens (2000) \\
\hline Murphy ve Olson (2008) & Marcinkowski ve Rehrig (1995) \\
\hline \multirow[t]{2}{*}{ Coyle (2005) } & Simmons (1995) \\
\hline & $\begin{aligned} \text { Roth (1992) } \\
\end{aligned}$ \\
\hline $\begin{array}{l}\mathrm{Bu} \text { çalışmada ise çevre okuryazarlığının dört } \\
\text { boyutunu da dahil ederek incelenmesinin her- } \\
\text { hangi bir eksik bovut kalmaması acısından }\end{array}$ & $\begin{array}{l}\text { daha uygun olacağı düşünülmüştür. Çevre } \\
\text { okuryazarlığı alt boyutlarından kabul edilen } \\
\text { cevre hiloisi cevreve ait sorunlar bu sorunlara }\end{array}$ \\
\hline
\end{tabular}


aranan çözüm yolları, ekolojik alandaki gelişmeler ve doğa hakkındaki tüm bilgiler demektir. Çevreye yönelik tutum ise çevre sorunlarından kaynaklanan korkular, kızgınlıklar, huzursuzluklar, değer yargıları ve çevre sorunlarının çözümüne hazır bulunuşluk gibi kişilerin çevreye yararlı davranışlara olan olumlu veya olumsuz tavır ve düşüncelerinin hepsi olarak ifade edilmektedir (Erten, 2005). Davranış ise sorunları çözmeyi amaçlayan etkin ve planlanmış, düşünülmüş katılımı içerir. Çevresel davranışların kategorileri ikna etme, tüketici davranışı, fiziksel koruma davranışı, politik ve yasal davranışlardır (Volk ve Mcbeth, 2001). Çevreye yönelik eğilim ise bireylerin çevreye yönelik geliştirdikleri değerler, çevre duyarlılıkları, kontrol odakları, çevreye yönelik sorumlulukları ve çevre korumaya gönüllü katılmayı isteyip istemedikleri (niyet) olarak tanımlanmaktadır (Güler, 2013).

Çevre okuryazarı bireyler, çevreye duyarlı, çevre bilgisine sahip ve çevreye yönelik olumlu tutum gösteren kişilerdir. Roth, (1992) çevre okuryazarlığını çevre sistemlerinin sağlığını algilama ve yorumlama kapasitesi ve bu sistemlerin sağlığını geliştirmek, yenilemek ve sürdürmek amacıyla uygun davranışlar göstermek olarak tanımlamaktadır. Rockcastle (1989) ise, çevre okuryazarlığını, insan ve onun canlı ve cansız şeylerden oluşan doğal çevre ile arasındaki etkileşimin bir anlayışı olarak tanımlar. Bu yüzden bireylerin çevre okuryazarlığına etki eten değişkenlerin belirlenmesi önemlidir. Bu sayede çevre okuryazarlık düzeyi yüksek bireyler yetiştirmek daha kolay olacaktır.

İlgili literatürde çevre okuryazarlığını ve onun alt boyutlarını etkileyen farklı değişkenler ifade edilmektedir. Rickinson (2001) çevreye yönelik tutuma etki eden ekonomik özellikler, anne baba tutumu ve yaşanılan çevre gibi faktörlerin olduğunu ifade etmiştir. Owens (2000) araştır- masında Wisconsin Çevre Okuryazarlığı anketini kullanarak 292 ortaokul kent öğretmeninin çevre okuryazarlığını dört boyut üzerinden değerlendirmiştir. Bunlar; 1) Çevreye karşı tutum, 11) Çevresel değişimi etkileyecek kendi güç ve sorumlulukları ile ilgili inançlar (eğilim), 111) Çevreye karşı kişisel davranışları ve eylemleri, 1v) Ekoloji ve çevresel konularla ilgili bilgiler olmak üzere sıralanmıştır. Diğer bir çalışmada ise Kibert (2000) çevre okuryazarl1ğının alt boyutları olan bilgi-tutum-davranış arasındaki ilişkileri analiz etmeyi ve çevre okuryazarlığı bileşenleri üzerindeki puan farklılıklarını cinsiyet, yaş ve sınıf düzeyine göre incelemiştir.

Varışlı (2009) araştırmasında 8. sınıf öğrencilerinin çevre okuryazarlıklarının (bilgi-tutumduyarlılık ve endişe) değerlendirilmesinde sosyo-demografik değişkenlerin (cinsiyet, anne-baba eğitim durumu ve mesleği ve çevre ile ilgili bilgileri edindikleri kaynaklar) etkisini incelemeyi amaçlamıştır. Araştırma sonucunda öğrencilerin çevre bilgilerinin az ya da orta düzeyde olduğu, çevreye karşı olan tutumlarının olumlu olduğu, çevre ile ilgili konularda duyarlı oldukları ve çevre sorunları ile ilgili endişelerinin olduğu belirlenmiştir. Erdoğan (2009) çalışmasında çevre okuryazarlığı boyutlarını dikkate alarak beşinci sınıf öğrencilerinin çevre okuryazarlık düzeylerini belirlemeyi ve bu öğrencilerin çevreye yönelik sorumlu davranışlarını etkileyen faktörleri araştırmayı amaçlamıştır. Araştırma sonucunda öğrencilerin orta düzeyde bir çevre okuryazarı olduğu tespit edilmiştir.

Karatekin ve Aksoy (2012) ise çalışmalarında Sosyal Bilgiler öğretmen adaylarının çevre okuryazarlık düzeyleri ile demografik özellikleri arasındaki ilişkiyi belirlemeyi amaçlamıştır. $\mathrm{Bu}$ amaç doğrultusunda 1587 öğretmen adayına "bilgi, eğilim, davranış ve bilişsel beceri" alt boyutlarından oluşan çevre okuryazarlığı anke- 
ti uygulanmıştır. Bu araştırmanın sonucunda Sosyal Bilgiler öğretmen adaylarının orta düzeyde çevre okuryazarı oldukları görülmüştür. Öğretmen adaylarının çevre okuryazarlıkları üzerinde gelir düzeyinin bir etkisi görülmezken; cinsiyet, çevre merak düzeyi, ailede çevreye duyarlı birey bulunma durumu, doğal alanlarda bulunma sıklığı, çevresel aktivitelere katılma sıklığı ve üniversitede çevre eğitimi dersi alma değişkenlerinin etkili olduğu görülmüştür.

Gittikçe önem kazanan çevre okuryazarlığının hangi değişkenlerden etkilendiğinin bulunması önemlidir. Bu amaçla bu çalışmada ortaokul öğrencilerinin çevre okuryazarlığına ve onun alt boyutlarına etki eden değişkenlerin incelenmesi amaçlanmıştır. Bu amaç doğrultusunda aşağıdaki sorulara yanıt aranmıştır:

1. Ortaokul öğrencilerinin çevre okuryazarlık alt boyutlarına cinsiyetin etkisi nedir?

2. Ortaokul öğrencilerinin çevre okuryazarlık alt boyutlarına anne ve babalarının eğitim düzeylerinin etkisi nedir?

3. Ortaokul öğrencilerinin çevre okuryazarlık alt boyutlarına sınıf düzeylerinin etkisi nedir?

\section{YÖNTEM}

$\mathrm{Bu}$ araştırmada ortaokul öğrencilerinin farklı değişkenlere göre çevre okuryazarlığı boyutlarının incelenmesi amaciyla betimsel tarama yöntemi kullanılmıştır.

\subsection{Araştırmanın Örneklemi}

Bu çalışmanın örneklemini toplam 713 ortaokul öğrencisi oluşturmaktadır. Örneklemi oluşturan öğrenciler Düzce ve Bartın illerindeki toplam 8 okuldan rastgele seçilmiştir. Örneklem seçimi yapılırken, bir evrenden, istatistiksel hesaplarla evreni temsil edebilme büyüklüğüne sahip ve tamamen rastgele yöntemle bir örneklem seçmenin mümkün olduğu "seçkisiz örnekleme" (Yıldırım ve Şimşek, 2005) yöntemi kullanılmıştır.

\subsection{Veri Toplama Araçları}

Bu çalışma kapsamında çevre okuryazarlığının alt boyutları olarak alınan "bilgi", "davranış", "duyuşsal eğilim" ve "tutum" için kullanılan ölçekler aşağıdaki gibidir:

Çevre Bilgi Testi: Erdoğan (2009) tarafından geliştirilmiştir. Testte 19 çoktan seçmeli ve 3 doğru-yanlış tipi soru bulunmaktadır. Öğrencilerin verdikleri doğru cevaplar " 1 " yanlış cevaplar ise " 0 " olarak puanlandırılmıştır. Araştırmacı tarafından yapılan geçerlilik ve güvenilirlik sonuçlarına göre testin KR21 güvenilirliği .69 olarak bulunmuştur. Ölçekten alınabilecek maksimum puan 22 'dir.

Çevreye Yönelik Duyuşsal Eğilim Ölçeğgi: Öğrencilerin çevreye yönelik eğilimlerini belirlemek amaciyla Wisconsin Center for Environmental Education tarafından yayınlanan ve Karatekin (2011) tarafından Türkçeye uyarlanan "Çevreye Yönelik Duyuşsal Eğilimler Ölçeği" kullanılmıştır. Ölçek 27 maddeden oluşmaktadır. "Hiç katılmiyorum (1)" dan "Kesinlikle katıliyorum (5)" a gidecek şekilde 5'li likert tipinde yapılandırılmıştır. Araştırmacı tarafından uyarlanan ölçeğin Cronbach Alpha güvenirlik katsayısı 0.78 olarak bulunmuştur. Ölçekten alınabilecek maksimum puan 135 , minimum puan ise $27^{\prime}$ dir.

Çevre Tutum Ölçeği: Ölçek Leeming, Dwyer ve Bracken (1995) tarafından geliştirilmiş ve Aslan, Sağır ve Cansaran (2008) tarafından Türkçe'ye uyarlanmıştır. İlköğretim öğrencilerinin çevreye yönelik tutumları değerlendirmeye yönelik geliştirilen ölçek 24 maddeden oluşmaktadır. "Kesinlikle katılmıyorum (1)" dan 
“Kesinlikle katıliyorum (5)" a gidecek şekilde 5’li likert tipinde yapılandırılmıştır. Ölçeğin Cronbach Alpha güvenirlik katsayısı 0,86 olarak bulunmuştur. Ölçekten alınabilecek maksimum puan 120 , minimum puan ise $24^{\prime}$ tür.

Çevreye Yönelik Sorumlu Davranış Ölçeği: Erdoğan (2009) tarafından geliştirilen bu ölçek yedili likert tipinde (hiç, bir, iki, üç, dört, beş ve beşten fazla) yapılandırılmıştır. Toplam 26 davranış cümlesinden oluşmaktadır. Öğrencilere bu ölçekte, verilen her bir davranışı son bir yıl içerisinde kaç kez yaptıkları (tekrarladıkları) sorulmuştur. Araştırmacı tarafından uyarlanan ölçeğin Cronbach Alpha güvenirlik katsayısı 0.89 olarak bulunmuştur. Ölçekten alınabilecek maksimum puan 156, minimum puan ise $0^{\prime}$ dir.

Kullanılan bu ölçeklerin yanı sıra öğrencilerin demografik özelliklerini belirlemek için kişisel bilgi formu da kullanılmıştır. Ölçekte yer alan madde sayıları dikkate alınarak bütün ölçeklerin aynı gün uygulanmaması uygun görülmüş ve toplam 3 haftalık süre içerisinde farklı günlerde uygulama gerçekleştirilmiştir. Her bir öğrencinin ölçeklere verdikleri yanıtların karışmaması için öğrenciler ayrı ayrı kodlanmış daha sonra ise bu veri seti birleştirilerek analizler yapılmıştır.

\subsection{Verilerin Analizi}

Verilerin analizinde SPSS paket programı kullanılmıştır. Her öğrencinin ölçeklere verdikleri cevapların toplamı hesaplanmıştır. Değerlendirmeler her bir ölçek ayrı ayrı kullanılarak yapılmıştır. Cinsiyetin öğrencilerin çevre okuryazarlığını oluşturan alt boyutlar üzerinde herhangi etkisinin olup olmadığının tespit edilmesinde bağımsız grup t-testi kullanılmıştır. Öğrencilerin bu boyutlar için elde ettikleri puanların üzerinde, sınıf düzeyleri, anne eğitim durumu ve baba eğitim herhangi bir etkisinin olup olmadığını bulmak için ise tek yönlü ANOVA testi uygulanmıştır. ANOVA uygulanırken olası bir istatistiksel anlamlılığın hangi gruplar arasında olduğunu belirlemek için; varyansların homojenlik durumu ayrıca test edilmiş ve homojen ise Tukey, homojen değil ise Tamhane testlerinden istifade edilmiştir. Çevre ile ilgili ders alan öğretmen adaylarının çevre eğitimine yönelik görüşlerinin değerlendirilmesinde ise yüzde ve frekans değerlerinden yararlanılmıştır. İstatistiksel hesaplamalarda anlamlılık düzeyi 0,05 olarak alınmıştır.

\section{BULGULAR}

Tablo 2. Öğrencilerin tanıtıcı özellikleri

\begin{tabular}{|c|c|c|c|c|c|c|c|c|}
\hline & \multicolumn{2}{|c|}{ Cinsiyeti } & \multicolumn{2}{|c|}{$\begin{array}{c}\text { Anne eğitim } \\
\text { düzeyi }\end{array}$} & \multicolumn{2}{|c|}{$\begin{array}{c}\text { Baba eğitim } \\
\text { düzeyi }\end{array}$} & \multicolumn{2}{|c|}{ Sınıf düzeyi } \\
\hline & $f$ & $\%$ & $f$ & $\%$ & $f$ & $\%$ & $f$ & $\%$ \\
\hline Erkek & 368 & 51,6 & & & & & & \\
\hline $\mathrm{K}_{1 \mathrm{Z}}$ & 345 & 48,4 & & & & & & \\
\hline Okuma yazma bilmiyor & & & 35 & 4,9 & 3 & 4 & & \\
\hline İlkokul & & & 252 & 35,3 & 190 & 26,6 & & \\
\hline Ortaokul & & & 153 & 21,5 & 193 & 27,1 & & \\
\hline Lise & & & 160 & 22,4 & 178 & 25,0 & & \\
\hline Üniversite-Lisansüstü & & & 113 & 15,8 & 149 & 20,9 & & \\
\hline 5. sinif & & & & & & & 170 & 23,8 \\
\hline 6. sinif & & & & & & & 195 & 27,3 \\
\hline 7. sinif & & & & & & & 180 & 25,2 \\
\hline 8. sinif & & & & & & & 168 & 23,6 \\
\hline Toplam & 713 & 100 & 713 & 100 & 713 & 100 & 713 & 100 \\
\hline
\end{tabular}


Elde edilen bulgular incelendiğinde örneklemin \%48,4'ünün kız, \%51,6'sının ise erkek olduğu, sınıf düzeyleri açısından ise birbirlerine oldukça yakın dağılım gösterdikleri anlaşıl- maktadır. Tablo 2'de yer alan ebeveyn eğitim durumları incelendiğinde ise ağırlıklı olarak ilkokul ve ortaokul mezunu oldukları anlaşılmaktadir.

Tablo 3. Öğrencilerin cinsiyet değişkenine göre verdikleri cevapların analizi

\begin{tabular}{|c|c|c|c|c|c|c|}
\hline Alt boyut & Cinsiyet & $N$ & $\bar{X}$ & SS & $t$ & $p$ \\
\hline \multirow{2}{*}{ bilgi } & Erkek & 368 & 14,83 & 2,042 & \multirow{2}{*}{, 353} & \multirow{2}{*}{0,724} \\
\hline & $\mathrm{K} 1 \mathrm{z}$ & 345 & 14,88 & 1,890 & & \\
\hline \multirow{2}{*}{$\begin{array}{l}\text { duyuşsal eği- } \\
\quad \text { lim }\end{array}$} & Erkek & 368 & 78,68 & 19,428 & \multirow{2}{*}{1,172} & \multirow{2}{*}{0,241} \\
\hline & $\mathrm{K}_{1 \mathrm{Z}}$ & 345 & 77,06 & 17,495 & & \\
\hline \multirow{2}{*}{ davranış } & Erkek & 368 & 80,21 & 18,766 & \multirow{2}{*}{2,213} & \multirow{2}{*}{0,027} \\
\hline & $\mathrm{K}_{1 \mathrm{Z}}$ & 345 & 76,57 & 24,882 & & \\
\hline \multirow{2}{*}{ tutum } & Erkek & 368 & 74,60 & 26,452 & \multirow{2}{*}{,968 } & \multirow{2}{*}{0,334} \\
\hline & $\mathrm{K}_{1 \mathrm{Z}}$ & 345 & 76,57 & 27,692 & & \\
\hline
\end{tabular}

Tablo 3 incelendiğinde cinsiyetin, çevre okuryazarlığının alt boyutlarından "çevreye yönelik sorumlu davranış" boyutu için anlamlı bir fark oluşturduğu anlaşılmaktadır $(\mathrm{p}<0,05)$. Puan ğinde bu farklılığın erkek öğrenciler lehine ortalamaları $\left(\bar{X}_{\mathrm{erk}}=80,21, \bar{X}_{\mathrm{kz}}=76,57\right)$ incelendiortaya çıktığı görülmektedir. Diğer boyutlar için ise cinsiyetin herhangi farklılığa sebep olmadığı yine Tablo 3'ten görülmektedir.

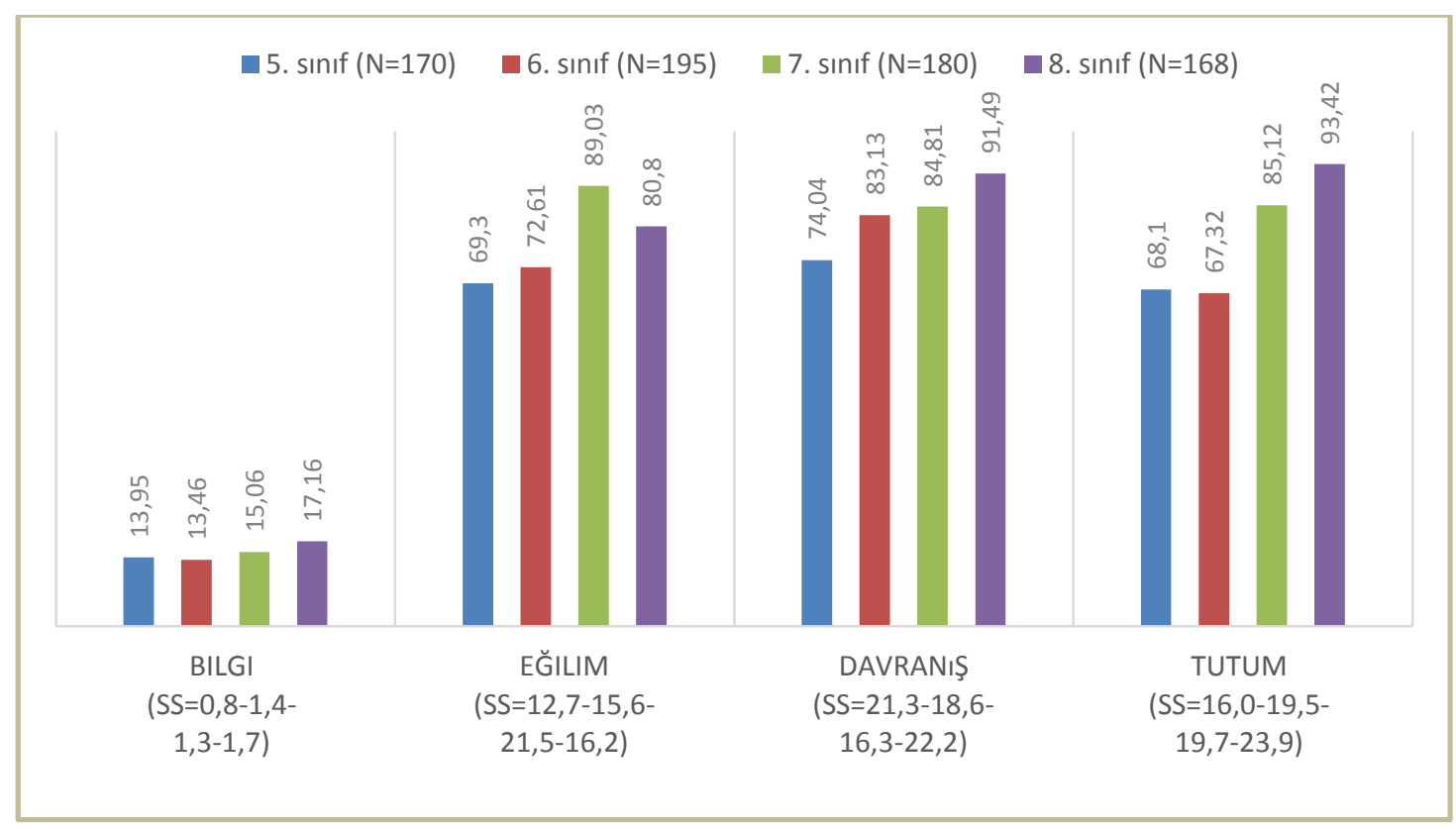

Şekil 1. Öğrencilerin sınıf düzeyine göre aldıkları puanların ortalamaları (parantez içleri sırasıyla standart sapma değerlerini göstermektedir)

Şekil 1'de öğrencilerin sınıf düzeylerine göre çevre okuryazarlığ 1 alt boyutlarına ait puan ortalamaları verilmiştir. Ortalama puanlar dikkate alındığında alt boyutlar için sınıf düzeyi arttıkça puanların da arttı̆̆ göze çarpmaktadir. 
Tablo 4. Öğrencilerin sınıf düzeylerine göre verdikleri cevapların analizi

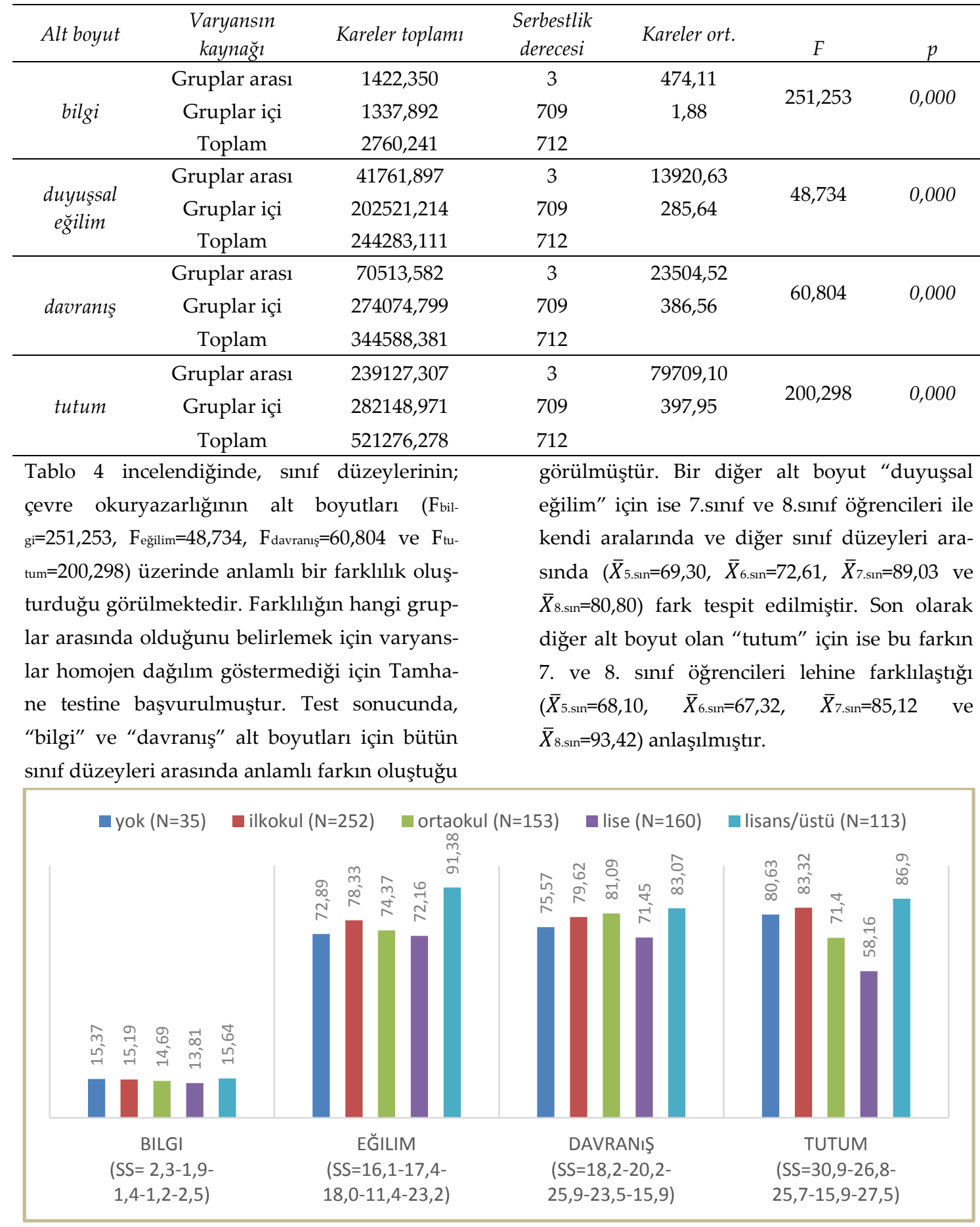

Şekil 2. Öğrencilerin anne eğitim düzeyine göre aldıkları puanların ortalamaları (parantez içleri sırasıyla standart sapma değerlerini göstermektedir)

Şekil 2'de öğrencilerin anne eğitim durumlar1na göre çevre okuryazarlığı alt boyutlarına ait puan ortalamaları verilmiştir. Ortalama puanlar dikkate alındığında, anne eğitim durumuna 
Tablo 6 incelendiğinde, öğrencilerin çevre okuryazarlığı boyutlarından "bilgi", "tutum" ve davranış için aldıkları puanlarda lise mezunu annelerin diğer mezuniyet derecelerine sahip annelerden daha fazla ön plana çıtı̆̆ görülmektedir. "duyuşsal eğilim" alt boyutu için ise üniversite mezunu annelerin diğer gruplara göre farklılaştığı görülmektedir (ortalama puanlar için Şekil 2).
Şekil 3'de öğrencilerin baba eğitim düzeylerine göre çevre okuryazarlığı alt boyutlarına ait puan ortalamaları verilmiştir. Ortalama puanlar dikkate alındığında alt boyutlar için babanın eğitim düzeyi arttıkça puanların da arttığı göze çarpmaktadır.

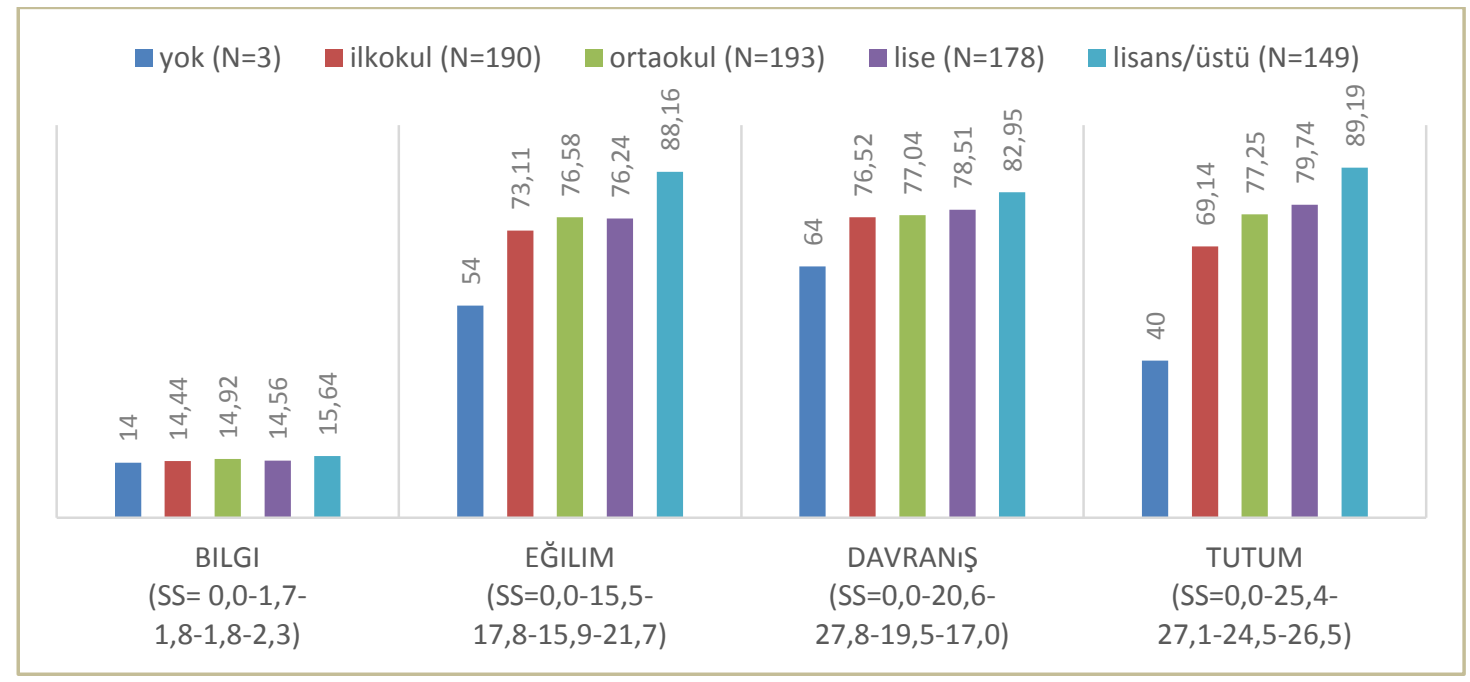

Şekil 3. Öğrencilerin baba eğitim düzeyine göre aldıkları puanların ortalamaları (parantez içleri sırasıyla standart sapma değerlerini göstermektedir)

Tablo 7. Öğrencilerin baba eğitim düzeylerine göre verdikleri cevapların analizi

\begin{tabular}{|c|c|c|c|c|c|c|}
\hline Alt boyut & $\begin{array}{c}\text { Varyansin } \\
\text { kaynağı }\end{array}$ & Kareler toplamı & $\begin{array}{c}\text { Serbestlik } \\
\text { derecesi }\end{array}$ & Kareler ort. & $F$ & $p$ \\
\hline \multirow{3}{*}{ bilgi } & Gruplar arası & 143,576 & 4 & 35,89 & \multirow{3}{*}{9,712} & \multirow{3}{*}{0,000} \\
\hline & Gruplar içi & 2616,665 & 708 & 3,69 & & \\
\hline & Toplam & 2760,241 & 712 & & & \\
\hline \multirow{3}{*}{$\begin{array}{c}\text { duyuşsal } \\
\text { eğilim }\end{array}$} & Gruplar arası & 22588,525 & 4 & 5647,13 & \multirow{3}{*}{18,035} & \multirow{3}{*}{0,000} \\
\hline & Gruplar içi & 221694,586 & 708 & 313,12 & & \\
\hline & Toplam & 244283,111 & 712 & & & \\
\hline \multirow{3}{*}{ davranış } & Gruplar arası & 4729,249 & 4 & 1182,31 & \multirow{3}{*}{2,463} & \multirow{3}{*}{0,044} \\
\hline & Gruplar içi & 339859,132 & 708 & 480,02 & & \\
\hline & Toplam & 344588,381 & 712 & & & \\
\hline \multirow{3}{*}{ tutum } & Gruplar arası & 45908,305 & 4 & 11477,07 & \multirow{3}{*}{17,094} & \multirow{3}{*}{0,000} \\
\hline & Gruplar içi & 475367,972 & 708 & 671,42 & & \\
\hline & Toplam & 521276,278 & 712 & & & \\
\hline
\end{tabular}


Tablo 7 incelendiğinde, baba eğitim düzeylerinin; çevre okuryazarlığının alt boyutları (Fbilgi=9,712, $F_{\text {eğilim }}=18,035, \quad F_{\text {davranış }}=2,463$ ve $F_{t u-}$ tum=17,094) üzerinde anlamlı bir farklılık oluşturduğu görülmektedir. Farklılığın hangi gruplar arasında olduğunu belirlemek için varyanslar homojen dağılım göstermediği için Tamha- ne testine başvurulmuştur. Test sonuçları Tablo 8 'da sunulmuştur (Tabloda yalnızca $p$ değerleri verilmiş olup, öğrencilerin çevre okuryazarl1ğının alt boyutlarına ait puanların hangi mezun grupları arasında farklılaştı $\breve{g}_{1}$ * işareti ile gösterilmiştir).

Tablo 8. Öğrencilerin baba eğitim düzeylerine göre verdikleri cevapların post hoc test sonuçları (sadece $p$ değerleri verilmiştir, $\left.{ }^{*} \mathrm{p}<, 05\right)$

\begin{tabular}{cccccc}
\hline Alt boyut & baba eğitim & ilkokul & ortaokul & lise & lisans \\
\hline \multirow{4}{*}{ bilgi } & yok &, $007^{*}$ &, $000^{*}$ &, $001^{*}$ &, $000^{*}$ \\
& ilkokul & &, $091^{*}$ &, 999 &, $000^{*}$ \\
& ortaokul & & &, 453 &, $019^{*}$ \\
& lise & & & &, $000^{*}$ \\
\hline \multirow{3}{*}{$\begin{array}{c}\text { duyuşsal } \\
\text { eğilim }\end{array}$} & yok &, $000^{*}$ &, $000^{*}$ &, $000^{*}$ &, $000^{*}$ \\
& ilkokul & &, 360 &, 446 &, $000^{*}$ \\
& ortaokul & & & 1,000 &, $000^{*}$ \\
\hline \multirow{4}{*}{ lise } & & & &, $000^{*}$ \\
& yokranış &, $000^{*}$ &, $000^{*}$ &, $000^{*}$ &, 150 \\
& ilkokul & & 1,000 &, 985 &, 254 \\
\hline & ortaokul & & & 1,000 &, $000^{*}$ \\
& lise & & & &, $000^{*}$ \\
tutum & yok &, $000^{*}$ &, $000^{*}$ &, $000^{*}$ &, $000^{*}$ \\
\hline
\end{tabular}

Tablo 8 incelendiğinde, çevre okuryazarlığı alt boyutları için baba eğitim durumunun lisans/lisansüstü düzeyde daha belirleyici olduğu göze çarpmaktadır (Ortalama puanlar için şekil 3). Okuma yazma bilmeyen babalar ile diğer eğitim düzeylerinde de istatistiksel olarak anlamlı fark bulunmuştur. Ancak bu farklılığın hem okuma yazma bilmeyen baba sayısının çok az $(\mathrm{N}=3)$ olması hem de puan ortalamalarının çok aşağıda kalmasından kaynaklandığı ifade edilebilir.

\section{SONUÇ ve ÖNERİLER}

Araştırmada ortaokul öğrencilerinin çevresel okuryazarlık alt boyutlarının farklı değişkenlerle ilişkisi araştırılmıştır. Bu sayede gittikçe önem arz eden çevre okuryazarlığına etki eden faktörlerin belirlenmesine yardımcı olunması amaçlanmaktadır. Elde edilen bulgulara göre çalışmanın sonuçları ve ilgili literatür ile karşılaştırılması aşağıdaki gibi şekillenmiştir.

Çevre okuryazarlık alt boyutu olan çevreye yönelik tutumlarında ortaokul öğrencilerinin cinsiyetlerine göre anlamlı farklılık görülmemiştir. Bu çalışmanın sonuçlarına paralel olarak Teyfur (2008), Özay-Köse (2010) ile Genç ve Genç (2013) çalışmalarında kız ve erkekler arasında çevreye yönelik tutum açısından anlamlı farklılık bulmamışlardır. Bunun yanında bazı çalışmalarda kızların erkeklere oranla anlamlı düzeyde çevreye yönelik olumlu tutum oluşturdukları ifade edilmektedir. (Alp, Ertepinar, Tekkaya ve Yilmaz, 2008; Atasoy ve Er- 
türk, 2008; Değirmenci, 2013; Deniş ve Genç, 2007; Ek, Kılıç, Öğdüm, Düzgün ve Şeker, 2009; Erol ve Gezer, 2006; Fortmann ve Kusel, 1990; Gezer, Çokadar, Köse ve Bilen, 2006; Gökçe, Kaya, Aktay ve Özden, 2007; GürbüzoğluYalmancı ve Gözüm, 2011; Iozzi, 1989; Kaya, Akıllı ve Sezek, 2009; Öcal, 2013; Özmen, Çetinkaya ve Nehir, 2005; Şama, 2003; Şenyurt, Temel ve Özkahraman, 2011). Ancak Carrier (2009) erkeklerin kılara oranla daha fazla çevreye yönelik tutuma sahip olduklarını belirlemiştir. Aydın ve Çepni (2012) de çalışmalarında erkeklerin kızlara oranla çevreye karşı daha fazla tutuma sahip oldukların ifade etmişlerdir.

Araştırma sonuçlarına göre öğrencilerin anne ve babalarının öğrenim durumlarına göre çevre okuryazarlığı alt boyutları açısından aralarında anlamlı farklılık bulunmuştur. Baba öğrenim durumunda öğrenim düzeyi arttıkça çevre bilgi, çevreye yönelik duyuşsal eğilim, davranış ve tutum alt boyutlarında anlamlı bir artış görülmektedir. Anne öğrenim durumunda ise lise ve lisans düzeyindeki öğrenim durumunda sahip annelerin diğer öğrenim düzeyindeki anneler göre anlamlı düzeyde farklı puanlar aldığ1 görülmektedir. Bu sonuçlara benzer şekilde Köse (2010) çalışmasında anne-baba öğrenim düzeyinin arttıkça öğrencilerin çevreye karşı tutumunda iyileşme olduğu belirlenmiştir. Bunun yanında Erol ve Gezer (2006) yaptıkları çalışmada öğrencilerin anne ve babalarının öğrenim durumunun onların çevreye yönelik tutumlarına olan etkisi açısından anlamlı bir ilişki bulunmadığını ifade etmişlerdir. Ancak literatürdeki bu çalışmaların bulgularıyla, yapılan bu araştırma ile elde edilen sonuçlar kıyaslandığında lise mezunu anneler açısından bir farklılık göze çarpmaktadır. Lise mezunu annelerin, çocukları üzerindeki çevre etkisinin diğer mezuniyet derecesine sahip annelere göre daha fazla olduğu bulunmuştur ki bu sebepleri açısından tartışılması gereken bir konu olarak daha sonraki çalışmalara önerilebilir.

Bunun yanında, Uzun ve Sağlam, (2007) yaptıkları çalışmada, ortaöğretim programında seçmeli olarak verilen "Çevre ve İnsan" dersi ile Gönüllü Çevre Kuruluşlarının öğrencilerin çevreye yönelik bilgi ve tutumlarına etkisi araştırılmıştır. Araştırma sonuçlarına göre, "Çevre ve İnsan" dersini alan ve almayan öğrencilerin çevreye yönelik bilgi ve tutum ortalamaları arasında, dersi alan öğrencilerin lehine anlamlı bir farkın olduğu tespit edilirken; gönüllü çevre kuruluşlarında aktif olarak çalışma durumlarına göre yapılan değerlendirmede, öğrencilerin çevresel tutum ve çevre bilgisi ortalamaları arasında anlamlı bir fark bulunmamıştır. May (2000) ise yaptığ çalışmada çevre eğitiminde öğretim koşulları, öğretmen yeterlikleri ve öğretim uygulamalarının etkili olduğunu belirtmiştir. Öğretim uygulamalarında proje tabanlı öğrenmenin kullanılması tutumu olumlu etkilediği görülmektedir. Ayr1ca Cheong (2005) kısa süreli proje çalışmalarının bile öğretmen adaylarının gerçek toplumsal problemleri (çöp, su ve kanalizasyon, terkedilmiş toprak, erozyon, kağıt geri dönüşümü, kaplumbağa koruma) çözmeyi denemek için yeterli olduğunu belirtmiştir. Çevre okuryazarlığının, çevre eğitiminin en önemli hedefi olduğu düşünülürse; özellikle sürdürülebilirlik kavramının ön plana çıkarıldığı günümüz yaklaşımlarında bireylerde çevre okuryazarlığının geliştirilmesi için küçük yaşlardan eğitimlerin başlatılması önerilebilir. Bunun yanında sadece öğrenci bazında değil ebeveyn düzeyinde de etkinlik çalışmalarının işe koşularak aile ortamı içinde bir bütünlük ile çevreye karşı olumlu davranışların geliştirilmesi, çevre bilincinin arttırılması, çevre koruma bilgisinin verilmesi gerekmektedir. 


\section{Kaynakça}

Alp, E., Ertepinar, H., Tekkaya, C. ve Yılmaz, A. (2008). A survey on Turkish elementary school students' environmental friendly behaviours and associated variables, Environmental Education Research, 14(2), 129-143.

Altınöz, N. (2010). Fen bilgisi öğretmen adaylarının çevre okuryazarlık düzeyleri. Yayımlanmamış Yüksek Lisans Tezi, Sakarya Üniversitesi Fen Bilimleri Enstitüsü, Sakarya.

Aslan, O., Sağır, Ş.U. ve Cansaran, A (2008). Çevre tutum ölçeği uyarlanması ve ilköğretim öğrencilerinin çevre tutumlarının belirlenmesi. Selçuk Üniversitesi Ahmet Keleşoğlu Eğitim Fakültesi Dergisi, 25 $283-295$.

Atasoy, E. ve Ertürk, H. (2008). İlköğretim öğrencilerinin çevresel tutum ve çevre bilinci üzerine bir alan araştırması. Erzincan Eğitim Fakültesi Dergisi, 10 (1), 105-122.

Atasoy, E. (2006). Çeore İçin Eğitim. Çocuk-Doğa Etkileşimi. Bursa: Ezgi Kitabevi,

Aydın, F. ve Çepni, O. (2012). İlköğretim ikinci kademe öğrencilerinin çevreye yönelik tutumlarının bazı değişkenler açısından incelenmesi (Karabük ili örneği). Dicle Üniversitesi Ziya Gökalp Eğitim Fakültesi Dergisi, 18, 189-207.

Balkan Kıyıcı, F. (2009). Çevre eğitimi. V. Sevinç (Ed.), Eğitim fakülteleri için genel çevre bilimi, 175- 183. Ankara: Maya Akademi.

Bergman, B. G. (2015). Assessing impacts of locally designed environmental education projects on students' environmental attitudes, awareness, and intention to act. Environmental Education Research, DOI: 10.1080/13504622.2014.999225

Carrier, S. J. (2009). Environmental education in the schoolyard: learning styles and gender, The Journal of Environmental Education, 40, 3; 2-12.

Cheng, T.M., and Wu, H.C. (2015). How do environmental knowledge, environmental sensitivity, and place attachment affect environmentally responsible behavior? An integrated approach for sustainable island tourism. Journal of Sustainable Tourism, 23(4), 557-576, DOI: 10.1080/09669582.2014.965177

Cheong, I.P.A. (2005). Educating pre-service teachers for a sustainable environment, Asia-Pasific Journal of Teacher Education, 33, (1): 97-110.

Değirmenci, M. (2013). ̇lköğretim öğrencilerinin çevreye karşı tutumlarının farklı değişkenler açısından incelenmesi (Kayseri İli Örneği). Middle Eastern \& African Journal of Educational Research, 3: 59-68.

Deniş, H. ve Genç, H. (2007). Çevre bilimi dersi alan ve almayan sınıf öğretmenliği öğrencilerinin çevreye ilişkin tutumları ve çevre bilimi dersindeki başarılarının karşılaştırılması, Mehmet Akif Ersoy Üniversitesi Ĕ̆itim Fakültesi Dergisi, 13, 20-26.

Dibgy, B. L. C. (2010). An examination impact of non-formal and informal learning on adult environmental knowledge, attitudes, and behaviors. Unpublished Doctoral Dissertation, University of Minnesota, U.S. 
Disinger, J. F., and Roth, C. E. (1992). Environmental literacy [ERIC/CSMEE digest]. Columbus, OH: ERIC Clearinghouse for Science, Mathematics, and Environmental Education (CSMEE), Ohio State University.

Ek, H.N., Kılıç N., Öğdüm, P., Düzgün, G. ve Şeker, S. (2009). Adnan Menderes Üniversitesinin farklı akademik alanlarında öğrenim gören ilk ve son sınıf öğrencilerinin çevre sorunlarına yönelik tutumları ve duyarlılıkları, Kastamonu Ĕ̆itim Dergisi, 17(1), 125-136.

Erdoğan, M. (2009). Fifth grade students' environmental literacy and the factors affecting students' environmentally responsible behaviors. Unpublished PhD thesis, Middle East Technical University, Ankara.

Erol, G. H. ve Gezer, K. (2006). Prospective of elementary school teachers' attitudes toward environment and environmental problems, International Journal of Environmental and Science Education, 1: 65-77.

Erten, S. (2005). Okul öncesi öğretmen adaylarında çevre dostu davranışların araştırılması. Hacettepe Üniversitesi Ĕ̆itim Fakültesi Dergisi, 28, 91-100.

Fah, L.Y. and Sirisena, A. (2014). Relationships between the knowledge, attitudes, and behaviour dimensions of environmental literacy: a structural equation modeling approach using smartpls. Journal for Educational Thinkers, 5, 119-144.

Fortmann L. ve Kusel J. (1990) New vaices old beliefs: Forest environmentalism among new and longstanding, Rural Residents Rural Sociology, 55(2): 214-232.

Genç, M. and Genç, T. (2013). The Investigation of Candidate Teachers' Attitudes towards Environment, Asian Journal of Instruction, 1 (1) (2013), 9-19.

Gezer, K., Çokadar, H., Köse, S. ve Bilen, K. (2006). Lise öğrencilerinin çevreye yönelik tutumlarının karşllaştırılması, Buldan Sempozyumu, 23-24 Kasım, 71-78,. Denizli: Pamukkale Üniversitesi.

Gökçe, N., Kaya, E., Aktay, S. ve Özden, M. (2007). İlköğretim öğrencilerinin çevreye yönelik tutumları. Elementary Education Online, 6(3): 452-468.

Goldman, D., Yavetz, B., Pe'er, S. (2006). Environmental literacy in teacher training in Israel: environmental behavior of new students. The Journal of Environmental Education, 38 (1), 3-22.

Gürbüzoğlu-Yalmancı, S. and Gözüm, A.İ.C. (2011), The investigation of Kafkas University of candidate teachers' attitudes towards environmental problems with respect to some variables, International Online Journal of Educational Sciences, 3(3): 1109-1132.

Hungerford, H., Peyton, R., and Wilke, R. (1980). Goals for curriculum development in environmental education. The Journal of Environmental Education, 11(3), 42-47.

Iozzi L.A. (1989). What research says to the educator part one: Environmental education and the affective domain, Journal of Environmental Education, 20,(3): 3-9.

Iozzi, L., Laveault, D., and Marcinkowski, T. (1990). Assessment of learning outcomes in environmental education. Paris: United Nations Educational, Scientific and Cultural Organization.

Karatekin, K (2011). Sosyal Bilgiler Öğretmen Adaylarının Çevre Okuryazarlık Düzeylerinin Belirlenmesi, Yayımlanmamış Doktora Tezi, Ankara: Gazi Üniversitesi Eğitim Bilimleri Enstitüsü. 
Karatekin, K. (2011). Sosyal Bilgiler Öğretmen Adaylarının Çevre Okuryazarlık Düzeylerinin Belirlenmesi, Yayımlanmamış Doktora Tezi, Ankara: Gazi Üniversitesi Eğitim Bilimleri Enstitüsü.

Karatekin, K. ve Aksoy, B. (2012). Sosyal bilgiler öğretmen adaylarının çevre okuryazarlık düzeylerinin çeşitli değişkenler açısından incelenmesi, Turkish Studies - International Periodical For The Languages, Literature and History of Turkish or Turkic, 7(1), 1423-1438.

Kaya, E., Akıllı, M. ve Sezek, F. (2009). Lise öğrencilerinin çevreye karşı tutumlarının cinsiyet açısından incelenmesi. Mehmet Akif Ersoy Üniversitesi Ĕ̆itim Fakültesi Dergisi, 9(18): 43-54.

Keleş, Ö., Uzun, N. and Varnac1-Uzun, F. (2010). The change of teacher candidates' environmental consciousness, attitude, thought and behaviors with nature training project and the assessment of its permanence, Electronic Journal of Social Sciences, 9(32): 384-401.

Kibert, C. N. (2000). An analysis of the correlations between the attitude, behavior, and knowledge components of environmental literacy in undergraduate university students. Unpublished Master Dissertation, The Graduate School of the University Of Florida, USA.

Köse, S., Savran-Gencer, A., Gezer, K., Erol, G. H. and Bilen, K. (2011). Investigation of undergraduate students' environmental attitudes, International Electronic Journal of Environmental Education,1(2): $85-96$.

Leeming, F. C., Dwyer, W. O. and Bracken, B. A. (1995). Children's Environmental Attitude and Knowledge Scale: Construction and validation. Journal of Environmental Education, 26(3), 22-31.

Leeming, F.C. ve Porter, B.E. (1997). Effects of participation in class activities on children's environmental attitudes and knowledge, Journal of Environmental Education, 28(2): 33-42.

Marcinkowski, T., and Rehrig, L. (1995). The secondary school report: A final report on the development, pilot testing, validation, and field testing of the Secondary School Environmental Literacy Assessment Instrument. In R. Wilke (Ed.), Environmental education literacy/needs assessment project: Assessing environmental literacy of students and environmental education needs of teachers: Final report for 1993-1995 (30-76). Stevens Point: University of Wisconsin-Stevens Point.

May, T. S. (2000). Elements of success in environmental education through practitioner eyes, Journal of Environmental Education, 31(3): 4-11.

Murphy, T.P. ve Olson, A. (2008). The third Minnesota report card on environmental literacy: A survey of adult environmental knowledge, attitudes and behavior. St. Paul, MN: Minnesota Pollution Control Agency http://www.seek.state.mn.us/publications/reportcard2008.pdf sitesinden 12.12.2013 tarihinde indirilmiştir).

Murphy, T.P. (2002). The Minnesota report card on environmental literacy. Hamline University, Center for Global Environmental Education. (ERIC Reproduction Service No. ED 474505)

Negev, M., Sagy, G., Garb, Y., Salzberg, A. and Tal, A. (2008). Evaluating the environmental literacy of Israeli elemantary and high school students. The Journal of Environmental Education, 39 (2), 3-20. DOI: 10.3200/JOEE.39.2.3-20. 
Öcal, T. (2013). Sosyal bilgiler öğretmen adaylarının çevre sorunlarına yönelik tutumlarının belirlenmesi [Determination of the attitudes of prospective social studies teachers towards environmental problems] Marmara Coğrafya Dergisi, 27: 333-352.

Owens, M.A. (2000). The environmental literacy of urban middle school teachers. Unpublished Doctoral Dissertation, Faculty of the Graduate School of EmoryUniversity, USA.

Özay-Köse, E. (2010). The factors that affect attitudes towards environment of secondary school students, Journal of Turkish Science Education, 7(3): 198-211.

Özmen, D., Çetinkaya, A.Ç. ve Nehir, S. (2005). Üniversite öğrencilerinin çevre sorunlarına yönelik tutumları, TSK Koruyucu Hekimlik Bülteni, 4(6), 330-344.

Rickinson, M.(2001). Learners and learning in environmental education: A critical review of the evidence, Environmental Education Research, 7(3): 207-320.

Rockcastle, V. (1989). Environmental literacy; Philosophy, content and strategies. Nature Study, 43(1-2), $8-9,22$.

Roth, C. E. (1992). Environmental literacy: Its roots, evolution and directions in the 1990s. (ERIC Document Reproduction Service No. ED348 235)

Şama, E. (2003). Öğretmen adaylarının çevre sorunlarına yönelik tutumları, [Teacher candidates' attitudes toward environmental problems], Gazi Eğitim Fakültesi Dergisi, 23(2): 99-110.

Şenyurt, A., Temel, A.B. ve Özkahraman, Ş. (2011) Üniversite öğrencilerinin çevresel konulara duyarlılıklarının incelenmesi, [Investigation of Attitude for Environmental Issues of University Students], S.D.Ü. Sağlık Bilimleri Enstitüsü Dergisi, 2(1): 18-15.

Simmons, D. (1995). Developing a framework for national environmental education standards [Working paper]. In D. Simmons (Ed.), The NAAEE standards project: Papers on the development of environmental education standards (9-58). Troy, OH: North American Association for Environmental Education.

Teksöz, G., Şahin, E., ve Ertepınar, H. (2010). Çevre okuryazarlığı, öğret men adayları ve sürdürülebilir bir gelecek. Hacettepe Üniversitesi Ĕ̈itim Fakültesi Dergisi, 39, 307-320.

Teyfur, E. (2008). İlköğretim öğrencilerinin akademik başarılarının ve çevre kulübü çalışmalarının çevreye yönelik tutumlarına olan etkisi (İzmir örneği), [The effect of academic achievement and environment club studies on primary school students towards the environment attitudes (Pattern of İzmir)], Ege Ĕ̆itim Dergisi, 9,(1): 131-149.

Uzun, N. ve Sağlam, N. (2007). Ortaöğretim öğrencilerinin çevreye yönelik bilgi ve tutumlarına "Çevre ve İnsan" dersi ile gönüllü çevre kuruluşlarının etkisi, [The effect of the course "man and environment" and voluntary environmental organizations on secondary school students' knowledge and attitude towards environment], Hacettepe University Journal of Education, 33: 210-218.

Varışl1, T. (2009). Evaluating eighty grade student's environmental literacy: the role of socio-demographic variables, Unpublished Master Dissertation, Middle East Technical University, Ankara. 
Volk, L. T., Mcbeth, W. (2001). Environmental literacy in the United States, (Eds: Hurold R. Hungerford, William J. Bluhm, Trudi L. Volk, John M. Ramsey). Essential Readings in Environmental Education 2. Edition, Illinois, Stipes Publishing L.L.C.

Wang, T.H. (2014). Implementation of Web-based argumentation in facilitating elementary school students to learn environmental issues. Journal of Computer Assisted Learning, 30, 479-496.

Yavetz, B., Goldman, D. and Pe'er, S. (2009). Environmental literacy of pre-service teachers in Israel: a comparison between students at the onset and end of their studies', Environmental Education Research, 15(4), 393-415.

Yavuz, M., Balkan Kıyıcı, F. ve Atabek Yiğit, E. (2014). İlköğretim II. Kademe Öğrencileri İçin Çevre Okuryazarlığı Ölçeği: Ölçek Geliştirme ve Güvenirlik Çalışması, [Environmental Literacy Scale For Secondary School Students: The Scale Development And Reliability]. Sakarya University Journal of Education, 4(3), 40-53.

Yıldırım, A. ve Şimşek, H. (2005). Sosyal Bilimlerde Nitel Araştırma Yöntemleri (5. Baskı). Ankara; Seçkin Yayınları. 


\section{Extended Summary}

For a sustainable life, it is important to develop people's attitudes, values, knowledge, skills and behaviors about protection of environment. Because of this reason environmental education is vital. One of the most important goals of environmental education programs is environmental literacy (Disinger and Roth, 1992; Hungerford, Peyton, and Wilke, 1980; Iozzi, Laveault, and Marcinkowski, 1990). Because environmental literacy is shown as the most effective way to deal environmental problems (Balkan Kıyıc1, 2009). Environmental educators (Karatekin ve Aksoy, 2012; Negev, Sagy, Garb, Salzberg ve Tal, 2008; Marcinkowski ve Rehrig, 1995; Simmons, 1995; Coyle, 2005; Goldman, Yavetz ve Pe'er, 2006) refers to different sub-dimensions like knowledge, behavior, attitude and tendency in order to define environmental literacy. It is important to find out that which variables effect the environmental literacy that has becoming more important day by day. For this reason, in this study it is aimed to demonstrate middle school students' environmental literacy levels with its sub-dimensions in terms of different factors which are gender, grade level and their parent's educational grade.

The sample of the study consisted of 713 secondary school students which were chosen from 8 schools in Duzce and Bartın cities. In order to determine students' environmental literacy's sub-dimensions levels, "environmental knowledge test" (Erdoğan, 2009), "affective tendencies scale" (Karatekin, 2011), "environmental attitude scale" (Aslan, Sağır ve Cansaran, 2008) and "environmentally responsible behavior scale" (Erdoğan, 2009) were used. Also a "personal information form" was used to gather about students' gender, grade level and parent's educational grade. The data was analyzed by SPSS packet programme with the help of independent $t$-test for gender variable and one way ANOVA for other variables. The significance level is 0.05 for statistical calculations.

As a result it was found that gender has no significant difference for knowledge, tendency and attitude sub-dimensions. But for behavior sub-dimension there is a difference between boys and girls which take place in favor of boys $\left(\bar{X}_{\text {boys }}=80,21, \bar{X}_{\text {girls }}=76,57\right)$. For grade level, it is seen that students' average scores for sub-dimensions are increase while grade level increase. Also grade level has significant difference for all sub-dimensions of environmental literacy. For students' father's education level, students' average scores are increasing with their father's educational level. But their mothers' education level is not show same result as fathers. Because students' which have high school graduated mothers scores are significant difference than others. 